\title{
Psychological distress resulting from the COVID-19 confinement is associated with unhealthy dietary changes in two Italian population-based cohorts
}

\author{
Marialaura Bonaccio ${ }^{1}$ ([) Simona Costanzo ${ }^{1} \cdot$ Francesca Bracone $^{1} \cdot$ Alessandro Gialluisi $^{1} \cdot$ Augusto Di Castelnuovo $^{2}$. \\ Emilia Ruggiero ${ }^{1}$ - Simona Esposito ${ }^{1}$ - Marco Olivieri ${ }^{3} \cdot$ Mariarosaria Persichillo ${ }^{1}$. Chiara Cerletti ${ }^{1}$. \\ Maria Benedetta Donati ${ }^{1}$. Giovanni de Gaetano ${ }^{1}$. Licia lacoviello ${ }^{1,4}$. for the Moli-LOCK Study Investigators
}

Received: 28 December 2020 / Accepted: 20 November 2021 / Published online: 30 November 2021

(c) The Author(s), under exclusive licence to Springer-Verlag GmbH Germany 2021

\begin{abstract}
Purpose To examine the relationship between psychological distress resulting from the COVID-19 lockdown and dietary changes.

Methods Cross-sectional analysis from 2 retrospective Italian cohorts recruited from May to September 2020: (1) The MoliLOCK cohort consists of 1401 participants from the Moli-sani Study $(n=24,325)$ who were administered a telephone-based questionnaire to assess lifestyles and psychological factors during confinement; (2) the ALT RISCOVID-19 is a web-based survey of 1340 individuals distributed throughout Italy who self-responded to the same questionnaire using Google ${ }^{\circledR}$ forms. Psychological distress was measured by assessments of depression (PHQ-9 and depressive items from the Screening Questionnaire for Disaster Mental Health- SQD-D), anxiety (GAD-7), stress (PSS-4), and post-traumatic stress disorder (SQD-P). Diet quality was assessed either as changes in consumption of ultra-processed foods (UPF) or adherence to Mediterranean $\operatorname{diet}(\mathrm{MD})$.

Results In ALT RISCOVID-19, increased UPF intake was directly associated with depression (both PHQ-9 and SQD-D; $p<0.0001)$, anxiety $(p<0.0001)$, stress $(p=0.001)$ and SQD-P $(p=0.001)$; similar results were obtained in the Moli-LOCK cohort except for perceived stress. When psychometric scales were analysed simultaneously, only depression (SQD-D) remained associated with UPF (both cohorts). In both cohorts, psychological distress poorly influenced changes toward an MD, except for depression (SQD-D) that resulted inversely associated in the ALT RISCOVID-19 participants ( $\beta=-0.16$; $95 \%$ CI - 0.26, - 0.06).

Conclusions Psychological distress from the COVID-19 confinement is directly associated with unhealthy dietary modifications in two Italian cohorts. In view of possible future restrictive measures to contain pandemic, public health actions are warranted to mitigate the impact of psychological distress on diet quality.
\end{abstract}

Keywords Psychological distress · Depression · Anxiety · Stress · Post-traumatic stress disorder · Lockdown · COVID-19 . Mediterranean diet $\cdot$ Ultra-processed foods

Moli-LOCK Study Investigators are listed in the Supplementary Appendix.

Marialaura Bonaccio

marialaura.bonaccio@moli-sani.org

1 Department of Epidemiology and Prevention, IRCCS NEUROMED, Via dell'Elettronica, 86077 Pozzilli, IS, Italy

2 Mediterranea Cardiocentro, Napoli, Italy

3 Associazione Cuore-Sano ONLUS, Campobasso, Italy

4 Department of Medicine and Surgery, Research Center in Epidemiology and Preventive Medicine (EPIMED), University of Insubria, Varese, Italy

\section{Introduction}

The coronavirus disease 2019 (COVID-19) has aggressively spread across the globe since late 2019 and, as of September 10, 2021, more than 220 million confirmed cases and over 4 million deaths have been reported [1].

The COVID-19 pandemic led the Italian government to enact unprecedented restrictive measures nationwide between March 9 and May 3 2020, in order to limit the fast spread transmission of the disease and the subsequent overwhelming of hospitals and health care systems [2]. 
During the lockdown, Italian residents were required to stay at home and only essential needs/services were permitted, with huge limitations in terms of working activities that were converted into home working as far as possible. As a consequence, daily routine was dramatically disrupted with potential negative effects on mental health and dietary habits: the latter are highly susceptible to psychological wellbeing $[3,4]$ and vice versa $[5,6]$.

The negative effects of lockdown on psychological health were already documented by studies analysing the effect of confinement during the SARS and MERS outbreaks in 2003 and 2012 [7, 8], and there is evidence that the psychological impact of quarantine is wide-ranging, substantial, can be long lasting [9] and may translate to severe distress eventually leading to significant psychological disorders [7, 9].

The effect of lockdown due to COVID-19 outbreak on mental health has been analysed in a number of studies so far, all concordant in indicating an increase in the prevalence of post-traumatic stress disorder [10], depression [10-13], anxiety [12,13], stress [12,13] and insomnia [13].

More recently, a study on 6,882 individuals from 59 Countries found that the COVID-19 pandemic has affected global mental health with increased prevalence of depression and anxiety [14]. Consistently, findings from a national Irish cohort indicated that the COVID-19 quarantine was associated with stress and significant increase in symptoms of depression and anxiety [15].

However, the impact of psychological distress induced by COVID-19 lockdown on dietary changes during confinement has been poorly investigated. Available data from a national French survey indicated that depression and anxiety clustered with unfavourable nutritional changes or behaviours during the lockdown period [16]. Similarly, data from a webbased survey in France revealed that a negative change in mental health was strongly associated with adverse changes in nutrition [17].

We therefore aimed at examining the association between psychological distress induced by the confinement with concurrent changes in diet quality, by using data on 2,741 Italian men and women from two population-based cohorts recruited from May 2020 to September 2020.

The rationale of our study relies on the well-established association between mental health and diet quality reported in a number of epidemiological settings [18-20].

\section{Methods}

\section{Study design and participants}

The Moli-LOCK Study The Moli-LOCK Study was designed as an observational cohort study aiming to retrospectively investigate dietary, lifestyle and psychosocial changes that possibly occurred after Italy's lockdown resulting from the COVID-19 pandemic, that is in the period of time between March 92020 and May 32020 . The population of the Moli-LOCK Study consists of a subgroup of men and women who had first been recruited in the larger Moli-sani Study cohort [21] in 2005-2010 $(n=24,325)$ and then re-examined in 2017-2020 $(n=2572)$. From May 2020 to September 2020, subjects were contacted by telephone by trained researchers to assess lifestyle, dietary and psychosocial changes during the confinement resulting from the COVID-19 pandemic. A total of 1,563 completed the questionnaire. As compared to the eligible sample who did not participate $(n=1009)$, individuals included in the study were slightly younger $(66.4 \pm 8.6$ vs $67.5 \pm 9.3 ; p$ value $<0.001$ for analysed vs excluded) and had higher education (upper secondary school or higher $=66.2 \%$ vs $61.5 \%$, respectively, $p=0.015$ ) while no differences were found for sex (men $=43.7 \%$ vs $47.1 \%$, respectively, $p=0.09$ ) and presence of chronic diseases (cardiovascular disease $=7.4 \%$ vs $9.3 \%, p=0.08$; cancer $=9.4 \%$ vs $9.2 \%, p=0.72$, respectively). The MoliLOCK study complies with the Declaration of Helsinki and was granted the approval of the Ethics Committee of the IRCCS Neuromed, Pozzilli (IS), Italy. Verbal informed consent during the telephone interview was obtained from all participants. After exclusion of participants with missing information on one or more psychometric scales and dietary data, we finally analysed 1401 subjects (Supplementary Fig. 1).

The ALT RISCOVID-19 Study ALT RISCOVID-19 is a cross-sectional web-based survey carried out among Italian adults aged $\geq 18$ years, resident in Italy during the confinement.

Data were collected through a structured self-administered questionnaire created in Google ${ }^{\circledR}$ Forms (Google LLC, Menlo Park, CA, USA). All subjects aged $\geq 18$ from the general population, residing in Italy during the Italian lockdown, with access to electronic devices and the Internet (e.g. personal computer, smartphone) and fluent in Italian were eligible.

Individuals were invited to participate in the survey via social media (Facebook ${ }^{\circledR}$ and Whatsapp ${ }^{\circledR}$ ) and e-mail contacts and the data collection occurred between June and September 2020. A total of 2060 subjects throughout Italy completed the survey.

Before starting the questionnaire, participants were informed about the aims of the study and were ensured that all data would be used for research purposes only; participants were required to accept the data sharing and privacy policy before taking part in the study. To protect the confidentiality of the participants, their personal information and data were anonymous, according to the provisions of the General Data Protection Regulation (GDPR 679/2016). 
The study was granted the approval of the Ethics Committee of the IRCCS Neuromed, Pozzilli (IS), Italy.

Participants with missing data on one or more psychometric scales and diet were excluded and the analytic sample consisted of 1340 subjects (Supplementary Fig. 1).

The ALT RISCOVID-19 survey and the Moli-LOCK study were registered on clinicaltrials.gov (NCT04422262).

\section{Data collection}

The ALT RISCOVID-19/Moli-LOCK questionnaire was constructed by the Department of Epidemiology and Prevention at the IRCCS Neuromed. The questionnaire was divided into modules including questions on sociodemographic characteristics, medical history, COVID-19 related aspects, dietary and lifestyle practices, psychological assessment and sources of information (Supplementary Appendix 1).

Psychological distress included assessment of depression, anxiety, stress and post-traumatic stress disorder (PTSD) that were respectively assessed by administration of validated versions of the Patients' Health Questionnaire (PHQ9) [22], the General Anxiety Disorder (GAD-7) [23], the 4-item Perceived Stress Scale (PSS-4) [24] and the Italian version of the Screening Questionnaire for Disaster Mental Health (SQD) [25] that includes nine items to assess PTSD (SQD-P) and six items to screen for depression at the same time (SQD-D).

Dietary changes were evaluated through a 41 -food-item questionnaire asking participants to indicate whether during lockdown their consumption of each food was increased, decreased or unchanged as compared to their usual intake just before the confinement (Supplementary Appendix 1).

Modifications in adherence to the MD were evaluated by computing a score (MD score) which scored foods according to their position in the Mediterranean diet pyramid: we assigned 1 point to increased consumption of highly recommended foods (e.g. fresh fruits, nuts and seeds, fresh vegetables) and minus 1 point if that consumption was decreased; conversely, decreased consumption of foods less frequent in the Mediterranean diet and for which it is recommended from low to moderate intake was given 1 point (e.g. red meat, white meat, milk and yogurt) and minus 1 point was assigned to increased intake. Unchanged intakes received 0 point (Supplementary Table 1). The MD score potentially ranged from -18 to 18 with higher values reflecting maximal switching to an MD.

Changes in UPF consumption was assessed through questions aimed at evaluating modifications possibly occurred during lockdown in the intake of 19 food items grouped according to the NOVA classification system based on the degree of food processing (Supplementary Table 2). Briefly, we categorized each food item into one of the following categories according to the extent and purpose of food processing: (1) unprocessed or minimally processed foods (e.g. fruits and vegetables, meat and fish); (2) processed culinary ingredients (e.g. butter, oils); (3) processed foods with salt, sugar, or oil (e.g. canned or bottled vegetables and legumes, canned fish); (4) UPF containing predominantly industrial substances and little or no whole food (e.g. carbonated drinks, processed meat, packaged snacks). For the purpose of the present analyses we used the fourth NOVA category.

We then computed an UPF score by assigning 1 point to increased intake, -1 point to decreased intake while unchanged intakes received 0 points (Supplementary Table 3). The score potentially ranges from -19 to 19 with higher values indicating an increase in UPF consumption during confinement.

\section{Statistical analyses}

Data are represented as number and percentage in parentheses $(\%)$ for categorical variables, or mean and standard deviation $( \pm \mathrm{SD})$ for continuous variables.

We tested the association of psychological distress (used as the exposure variable) with MD and UPF (dependent variables) by using multivariable linear regression analysis. Each psychometric score was scaled by its standard deviation so that regression coefficients indicate the variation in diet quality for 1 standard deviation change (cohort specific) for each measure of psychological distress. Associations were obtained by using the following models: Model 1 (adjusted for age and sex); multivariable Model 2 that was further controlled for main sociodemographic factors, namely geographical area (for ALT RISCOVID-19 only), living area, educational level, household income, marital status, number of cohabitants, occupational class, history of chronic diseases, diagnosis of $\geq 1$ diseases during confinement, use of psychoactive drugs before and during lockdown; multivariable Model 3 as in Model 2 and including all the psychometric scales simultaneously.

Missing data on covariates (educational level $=7$; household income $=381$; marital status $=23$; occupational class $=32$; number of cohabitants $=22$; living areas $=45$; history of chronic disease $=21$; diagnosis of disease during lockdown $=14$; use of psychoactive drugs during lockdown $=79$ ) were handled using multiple imputation (SAS PROC MI, followed by PROC MIANALYZE) to maximize data availability for all variables, avoid bias introduced by not-at-random missing (MNAR) data patterns and achieve robust results over different simulations ( $n=10$ imputed datasets).

Statistical tests were two-sided, and Bonferroni correction for multiple comparisons was applied to each analysis according to the number of independent tests carried out (see 
Tables). Data analysis was generated using SAS/STAT software, version 9.4 of the SAS System for Windows@2009.

\section{Results}

The pooled sample of 2741 subjects had a mean age of 58.1 years $( \pm 15.3)$ and included $40.8 \%$ men. The largest proportion lived in Southern Italy (75.0\%), was well-educated (postgraduate education 45\%), had high occupational class (43.2\% professional/managerial) and prevalently lived in pairs (73.1\%) (Table 1). MD score and UPF were inversely correlated (spearman correlation coefficient $=-0.11$; $p<0.0001$, data not shown), and correlations among psychometric scales were also moderate to high (Supplementary Table 4).

Overall, we found a slight increase in consumption of MD $(0.4 \pm 2.2)$ and a mild decrease in UPF intake $(-0.3 \pm 4.0)$ experienced during the lockdown (Table 1).

During confinement, in the ALT RISCOVID-19 cohort, all measures of psychological distress were consistently associated with an increase in UPF intake (PHQ-9: $\beta=0.16$, 95\% CI 0.10, 0.22; GAD-7: $\beta=0.14,95 \%$ CI 0.08, 0.20 ; PSS-4: $\beta=0.10,95 \%$ CI $0.04,0.16$; SQD-P: $\beta=0.10,95 \%$ CI $0.04,0.16$ and SQD-D: $\beta=0.17,95 \%$ CI $0.11,0.23$; Table 2, models 2 and Supplementary Fig. 2B).

On the contrary, psychological distress was unlikely to be relevant to changes in MD, with the exception of depressive symptoms as assessed by the SQD-D that resulted inversely associated with modifications toward an MD $(\beta=-0.09$, 95\% CI $-0.15,-0.03$; Table 2, models 2 and Supplementary Fig. 2A). Results from multivariable-adjusted model 3 , including all the psychometric scales simultaneously, showed that only depression as measured by the SQD-D was independently associated both with reduced adherence to an MD ( $\beta=-0.16,95 \% \mathrm{CI}-0.26,-0.06)$ and an increase in the intake of UPF ( $\beta=0.14,95 \%$ CI $0.05,0.24$ ) (Table 2 , models 3).

Analyses on 1,401 participants from the Moli-LOCK cohort revealed that perceived stress only predicted unfavourable dietary changes as reflected by a decrease of MD ( $\beta=-0.07 ; 95 \% \mathrm{CI}-0.13,-0.02$; Table 3 , models 2 and Supplementary Fig. 3A), although the statistical significance was not retained in model 3; all measures of psychological distress but perceived stress were associated with an increase in UPF intake (PHQ-9: $\beta=0.07,95 \%$ CI 0.02, 0.13; GAD-7: $\beta=0.08,95 \%$ CI $0.02,0.13$; SQD-P: $\beta=0.09,95 \%$ CI 0.03 , 0.14 and SQD-D: $\beta=0.13,95 \%$ CI $0.08,0.18$; Table 3 , models 2 and Supplementary Fig. 3B). Analyses from multivariable-adjusted model 3 , where all psychometric scales were considered simultaneously, showed that only the SQD-D remained significantly associated with UPF intake $(\beta=0.15$,
95\% CI 0.07, 0.23). Also, an inverse association of PSS-4 with UPF consumption was observed (Table 3, Models 3).

A number of diet-related factors resulted associated with psychological distress as well (Tables 4 and 5). Analyses on the ALT RISCOVID-19 sample showed major behavioural changes associated with depressive symptoms (SQD-D) while other indicators of psychological distress did not independently correlate with changes in eating behaviours during lockdown. In particular, depressive symptoms resulting from a traumatic life event were positively associated with higher body weight during confinement, an increase in the number of daily meals and reduced water intake (Table 4). Analyses from the Moli-LOCK cohort provided similar results, with the SQD-D being more strongly associated with changes in eating behaviours, as reflected by increased body weight, lower consumption of local food and more frequent food supplement use (Table 5). In this Moli-LOCK cohort we also observed some behavioural changes associated with PSS-4 (Table 5).

\section{Discussion}

We analysed the association between psychological distress and diet quality during the Italian nationwide confinement imposed from March 9 to May 32020 to contain the spread of the SARS-CoV-2 virus. Our findings from two Italian population-based cohorts indicated that higher levels of psychological distress experienced during lockdown were directly associated with unhealthy dietary changes in the same timeframe.

Diet quality was measured by an assessment of the consumption of either Mediterranean diet or UPF; in the ALTRISCOVID-19 web survey, participants with higher psychological distress reported an increase in highly processed foods, which are usually rich in sugar, saturated fats and dietary cholesterol, and a concurrent lower adherence to an MD. Similarly, in the Moli-LOCK cohort, psychological distress was linked to an increased consumption of UPF.

When psychometric scales were analysed simultaneously, only current depressive symptoms, as measured by the SQD$\mathrm{D}$, remained associated with unfavourable dietary changes in both cohorts.

This may be explained by the fact that, differently from the PHQ-9, the SQD-D is conceived to detect depressive symptoms immediately after the occurrence of a traumatic life event which is the case of the confinement resulting from the COVID-19 pandemic, and thus reinforcing the hypothesis that lockdown-induced depression could have had an impact on dietary changes.

Our findings align with those from a large study on UK individuals indicating that depressive symptoms during the COVID-19 lockdown were associated with an increased risk 
Table 1 Sociodemographic characteristics of the two cohorts analysed in this study

\begin{tabular}{|c|c|c|c|c|}
\hline & $\begin{array}{l}\text { Both } \\
\text { cohorts } \\
(n=2741)\end{array}$ & $\begin{array}{l}\text { ALT } \\
\text { RISCOVID-19 } \\
(n=1340)\end{array}$ & $\begin{array}{l}\text { Moli- } \\
\text { LOCK } \\
(n=1401)\end{array}$ & $p$ for difference \\
\hline Age $(y ;$ means $\pm S D)$ & $58.0 \pm 15.3$ & $47.8 \pm 14.0$ & $67.8 \pm 8.6$ & $<0.0001$ \\
\hline Sex (men) & 40.8 & 37.2 & 44.2 & 0.0002 \\
\hline Geographical areas & & & & $<0.0001$ \\
\hline Northern & 17.1 & 34.9 & 0.0 & \\
\hline Central & 6.3 & 12.7 & 0.1 & \\
\hline Southern and Islands & 75.0 & 49.0 & 99.9 & \\
\hline Missing data & 1.6 & 3.4 & 0.0 & \\
\hline Living area & & & & $<0.0001$ \\
\hline$>200,000$ inhabitants & 11.3 & 23.0 & 0.1 & \\
\hline$<200,000$ inhabitants & 12.0 & 24.3 & 0.1 & \\
\hline$<50,000$ inhabitants & 54.6 & 23.6 & 84.4 & \\
\hline Villages/rural areas & 22.1 & 29.1 & 15.4 & \\
\hline Educational level & & & & $<0.0001$ \\
\hline Lower secondary school or less & 18.4 & 4.1 & 32.0 & \\
\hline Upper secondary school & 36.5 & 26.1 & 46.5 & \\
\hline Postgraduate education & 44.8 & 69.6 & 21.2 & \\
\hline Missing data & 0.3 & 0.2 & 0.3 & \\
\hline Household income (EUR/y) & & & & $<0.0001$ \\
\hline$\leq 10,000$ & 5 & 5.1 & 5.4 & \\
\hline$>10,000 \leq 25,000$ & 27.4 & 22.2 & 32.4 & \\
\hline$>25,000 \leq 40,000$ & 29.4 & 22.0 & 36.6 & \\
\hline$>40,000 \leq 60,000$ & 12.7 & 14.0 & 11.5 & \\
\hline$>60,000$ & 11.3 & 19.9 & 3.0 & \\
\hline Missing data & 13.9 & 16.8 & 11.1 & \\
\hline Marital status & & & & $<0.0001$ \\
\hline Married/in couple & 72.3 & 61.8 & 82.3 & \\
\hline Single & 15.5 & 27.7 & 3.8 & \\
\hline Divorced & 5.5 & 7.4 & 3.6 & \\
\hline Widower & 5.9 & 2.0 & 9.7 & \\
\hline Missing data & 0.8 & 1.1 & 0.6 & \\
\hline Number of cohabitants & & & & $<0.0001$ \\
\hline None & 10.4 & 10.7 & 10.1 & \\
\hline 1 & 38.4 & 28.8 & 47.5 & \\
\hline 2 & 23.9 & 25.5 & 22.4 & \\
\hline$>2$ & 26.5 & 34.0 & 19.4 & \\
\hline Missing data & 0.8 & 1.0 & 0.6 & \\
\hline Occupational class & & & & $<0.0001$ \\
\hline Professional/managerial & 42.3 & 57.4 & 27.9 & \\
\hline Skilled non-manual & 31.1 & 22.9 & 39.0 & \\
\hline Skilled manual & 4.9 & 3.0 & 6.6 & \\
\hline Partly skilled/unskilled & 6.2 & 1.9 & 10.3 & \\
\hline Unemployed/unclassified & 14.4 & 13.1 & 15.6 & \\
\hline Missing data & 1.2 & 1.8 & 0.6 & \\
\hline History of chronic disease & & & & $<0.0001$ \\
\hline No & 89.6 & 85.4 & 93.6 & \\
\hline Yes & 9.7 & 13.4 & 6.1 & \\
\hline Missing data & 0.7 & 1.2 & 0.3 & \\
\hline Diagnosis of $\geq 1$ diseases during lockdown & & & & $<0.0001$ \\
\hline No & 95.4 & 92.2 & 98.6 & \\
\hline
\end{tabular}


Table 1 (continued)

\begin{tabular}{|c|c|c|c|c|}
\hline & $\begin{array}{l}\text { Both } \\
\text { cohorts } \\
(n=2741)\end{array}$ & $\begin{array}{l}\text { ALT } \\
\text { RISCOVID-19 } \\
(n=1340)\end{array}$ & $\begin{array}{l}\text { Moli- } \\
\text { LOCK } \\
(n=1401)\end{array}$ & $p$ for difference \\
\hline Yes & 4.1 & 6.9 & 1.3 & \\
\hline Missing data & 0.5 & 0.9 & 0.1 & \\
\hline Use of psychoactive drugs before lockdown & & & & 0.011 \\
\hline No & 95.4 & 95.4 & 95.3 & \\
\hline Yes & 4.6 & 4.6 & 4.7 & \\
\hline Use of psychoactive drugs during lockdown & & & & $<0.0001$ \\
\hline No & 93.8 & 90.5 & 97.0 & \\
\hline Yes & 3.3 & 5.5 & 1.1 & \\
\hline Missing data & 2.9 & 4.0 & 1.9 & \\
\hline PHQ-9 (means \pm SD) & $3.2 \pm 4.2$ & $4.6 \pm 4.8$ & $1.8 \pm 3.0$ & $<0.0001$ \\
\hline GAD-7 (means \pm SD) & $4.2 \pm 4.1$ & $5.4 \pm 4.4$ & $3.1 \pm 3.3$ & $<0.0001$ \\
\hline PSS-4 (means \pm SD) & $4.1 \pm 3.1$ & $5.2 \pm 3.1$ & $3.1 \pm 2.7$ & $<0.0001$ \\
\hline SQD-Post traumatic subscale (means \pm SD) & $1.5 \pm 1.9$ & $1.9 \pm 2.1$ & $1.1 \pm 1.6$ & $<0.0001$ \\
\hline SQD-Depression subscale (means \pm SD) & $1.2 \pm 1.5$ & $1.7 \pm 1.7$ & $0.6 \pm 1.1$ & $<0.0001$ \\
\hline Change in MD (means $\pm \mathrm{SD})$ & $0.4 \pm 2.2$ & $0.6 \pm 2.6$ & $0.2 \pm 1.6$ & $<0.0001$ \\
\hline Change in UPF (means \pm SD) & $-0.3 \pm 4.0$ & $-0.9 \pm 5.5$ & $0.3 \pm 1.6$ & $<0.0001$ \\
\hline
\end{tabular}

Values are presented as percentages unless otherwise stated

$P$ values are adjusted for age and sex

$P H Q-9$ Patients' Health questionnaire, GAD-7 General anxiety disorder scale, $P S S-4$ Perceived stress scale, $S Q D$ Screening Questionnaire for Disaster Mental Health, $S Q D-P$ Post-traumatic Stress Disorder, $S Q D-D$ Depressive symptoms, MD Mediterranean diet (score - 18 to 18), UPF Ultra-processed food (score - 19 to 19)

of experiencing any changes in eating behaviours possibly through emotional eating, even though this potential link could not be directly assessed [26].

Our a priori research hypothesis was that psychological distress during confinement, possibly resulting from disruption of daily life and social isolation, would negatively impact diet quality and not vice versa, due to the relatively short timeframe in which such association has been analysed. Mental health can be influenced by diet through several mechanisms, including chronic inflammation as follows: healthy diets are usually associated with lower inflammation $[27,28]$ while raised inflammation has been associated with a broad range of psychiatric disorders [29]; thus, positive health-related behaviours might reduce the risk of adverse mental health also by a favourable modulation of the inflammatory pathway. Therefore, it is likely that mental health and dietary habits show a bidirectional relationship, especially over long time ranges. However, in our study the association of psychological distress and modification of diet quality has been investigated within a two-month period, which is a relatively short period of time for the inflammatory process possibly caused by unhealthy diets to have an effect on mental health.

The association between psychological health and diet is largely supported by previous investigations conducted not in a context of pandemics $[4-6,18,19]$, but only a few studies to date have analysed the association of psychological distress resulting from COVID-19 lockdown with diet quality during the same timeframe.

An early investigation on 5545 Spanish adults conducted 2 weeks after the nationwide lockdown highlighted that a healthy and balanced diet was predictive of reduced levels of anxiety symptoms and depression [30]. A national survey on 42,000 Brazilian adults found that people with previous diagnosis of depression were at higher risk of unhealthy behaviours during the COVID19 pandemic quarantine, including low frequency of fruit or vegetable consumption and elevated frequency of UPF intake [31].

A small-sized web-based survey on French adults highlighted that the lockdown led to a decrease in nutritional quality of diet on average, which could be partly explained by an increase of mood as a food choice motive [32]. In the NutriNet-Santé cohort study including nearly 40,000 French adults [16], higher scores for depression and anxiety clustered with unfavourable nutritional changes or behaviours during the lockdown period. More recent studies are concordant in showing that psychological distress experienced during the lockdown and dietary changes are highly correlated; indeed, a community-based cross-sectional study on Portuguese adults indicated that there was a significant indirect effect of the experienced psychosocial impact of 
Table 2 Association of psychological factors with changes in adherence to Mediterranean diet (MD) and consumption of ultra-processed foods (UPF) during the Italian lockdown resulting from the COVID-
19 pandemic (March 9-May 3, 2020) in the ALT RISCOVID-19 web-based survey $(n=1340)$ using data obtained from multiple imputation

\begin{tabular}{|c|c|c|c|c|c|c|c|c|}
\hline & \multicolumn{4}{|c|}{ Change in MD } & \multicolumn{4}{|c|}{ Change in UPF } \\
\hline & $\begin{array}{l}\text { Regression } \\
\text { coefficient } \beta\end{array}$ & Lower $95 \%$ CI & Upper 95\% CI & $p$ value & $\begin{array}{l}\text { Regression } \\
\text { coefficient } \beta\end{array}$ & Lower 95\%CI & Upper 95\% CI & $p$ value \\
\hline \multicolumn{9}{|l|}{ PHQ-9 } \\
\hline Model 1 & -0.04 & -0.10 & 0.01 & 0.12 & 0.15 & 0.09 & 0.20 & $<.0001$ \\
\hline Model 2 & -0.05 & -0.11 & 0.02 & 0.15 & 0.16 & 0.10 & 0.22 & $<.0001$ \\
\hline Model 3 & -0.02 & -0.12 & 0.08 & 0.67 & 0.07 & -0.03 & 0.17 & 0.15 \\
\hline \multicolumn{9}{|l|}{ GAD-7 } \\
\hline Model 1 & -0.03 & -0.09 & 0.02 & 0.23 & 0.14 & 0.08 & 0.19 & $<.0001$ \\
\hline Model 2 & -0.03 & -0.09 & 0.03 & 0.38 & 0.14 & 0.08 & 0.20 & $<.0001$ \\
\hline Model 3 & -0.01 & -0.10 & 0.09 & 0.87 & 0.06 & -0.03 & 0.16 & 0.20 \\
\hline \multicolumn{9}{|l|}{ PSS-4 } \\
\hline Model 1 & -0.01 & -0.06 & 0.05 & 0.84 & 0.10 & 0.05 & 0.16 & 0.0004 \\
\hline Model 2 & 0.01 & -0.05 & 0.07 & 0.75 & 0.10 & 0.04 & 0.16 & 0.001 \\
\hline Model 3 & 0.08 & 0.00 & 0.16 & 0.06 & -0.02 & -0.10 & 0.06 & 0.60 \\
\hline \multicolumn{9}{|l|}{ SQD-P } \\
\hline Model 1 & -0.03 & -0.09 & 0.02 & 0.28 & 0.10 & 0.05 & 0.16 & 0.0002 \\
\hline Model 2 & -0.03 & -0.09 & 0.03 & 0.32 & 0.10 & 0.04 & 0.16 & 0.001 \\
\hline Model 3 & 0.07 & -0.03 & 0.16 & 0.16 & -0.06 & -0.15 & 0.03 & 0.18 \\
\hline \multicolumn{9}{|l|}{ SQD-D } \\
\hline Model 1 & -0.08 & -0.14 & -0.03 & 0.004 & 0.16 & 0.11 & 0.22 & $<.0001$ \\
\hline Model 2 & -0.09 & -0.15 & -0.03 & 0.003 & 0.17 & 0.11 & 0.23 & $<.0001$ \\
\hline Model 3 & -0.16 & -0.26 & -0.06 & 0.001 & 0.14 & 0.05 & 0.24 & 0.004 \\
\hline
\end{tabular}

Model 1 obtained from multivariable-adjusted linear regression including age and sex

Model 2 obtained from multivariable-adjusted linear regression including age, sex, geographical area, living area, educational level, household income, marital status, number of cohabitants, occupational class, history of chronic diseases, diagnosis of $\geq 1$ diseases during lockdown and use of psychoactive drugs before or during lockdown

Model 3 as in model 2 and including all psychometric scales simultaneously. Significant associations surviving Bonferroni correction for multiple testing $(\alpha=0.01)$ are highlighted in bold

PHQ-9 Patients' Health questionnaire, GAD-7 General anxiety disorder scale, PSS-4 Perceived stress scale, SQD Screening Questionnaire for Disaster Mental Health, $S Q D-P$ Post-traumatic Stress Disorder, $S Q D-D$ Depressive symptoms

COVID-19 pandemic on disordered eating behaviours mediated through psychological distress [33].

An online survey on a small sample of Italians provided evidence of the negative effects of isolation and lockdown on emotional wellbeing, and, relatedly, on eating behaviours [34]. Perceived worsened diet quality during the COVID-19 pandemic possibly led to higher odds for clustered mental ill-health, including anxiety and depressive symptoms in a large cohort of Swedish people [35].

A favourable association between psychological health and an MD has been previously reported in numerous crosssectional [36-38] and longitudinal analyses [39, 40] from population studies; consistently, a diet rich in UPF was unfavourably associated with mental health rather being associated with increased risk of incident depression [41, 42], while the association with other psychological disorders, such as stress or anxiety, has not been extensively addressed, with few exceptions [43]. Our study is one of the first to provide evidence of an association between anxiety, stress and PTSD symptoms with a diet rich in UPF.

The role of psychological distress, including depression and anxiety, in the development and progression of cardiovascular disease is well established $[44,45]$ as well as that of unhealthy and unbalanced diets which are associated with a variety of negative health outcomes [46, 47].

\section{Strength and limitations}

A major strength of this study is the use of two populationbased cohorts to examine the impact of psychological stress resulting from the lockdown on diet quality modifications. Also, the study relies on the use of a number of covariates which limit at least in part confounding, and data were collected shortly after the end of the Italian lockdown. 
Table 3 Association of psychological factors with changes in adherence to Mediterranean diet (MD) and consumption of ultra-processed foods (UPF) during the Italian lockdown resulting from the COVID-
19 pandemic (March 9-May 3, 2020) in the Moli-LOCK cohort $(n=1401)$ using data obtained from multiple imputation

\begin{tabular}{|c|c|c|c|c|c|c|c|c|}
\hline & \multicolumn{4}{|c|}{ Change in MD } & \multicolumn{4}{|c|}{ Change in UPF } \\
\hline & $\begin{array}{l}\text { Regression } \\
\text { coefficient } \beta\end{array}$ & Lower $95 \%$ CI & Upper $95 \%$ CI & $p$ value & $\begin{array}{l}\text { Regression } \\
\text { coefficient } \beta\end{array}$ & Lower 95\% CI & Upper 95\% CI & $p$ value \\
\hline \multicolumn{9}{|l|}{ PHQ-9 } \\
\hline Model 1 & -0.05 & -0.10 & 0.01 & 0.09 & 0.09 & 0.03 & 0.14 & 0.001 \\
\hline Model 2 & -0.06 & -0.11 & -0.0003 & 0.05 & 0.07 & 0.02 & 0.13 & 0.01 \\
\hline Model 3 & -0.01 & -0.09 & 0.07 & 0.79 & 0.04 & -0.04 & 0.11 & 0.38 \\
\hline \multicolumn{9}{|l|}{ GAD-7 } \\
\hline Model 1 & -0.05 & -0.10 & 0.003 & 0.07 & 0.09 & 0.04 & 0.14 & 0.001 \\
\hline Model 2 & -0.06 & -0.11 & -0.002 & 0.04 & 0.08 & 0.02 & 0.13 & 0.01 \\
\hline Model 3 & -0.01 & -0.10 & 0.07 & 0.75 & 0.05 & -0.04 & 0.13 & 0.29 \\
\hline \multicolumn{9}{|l|}{ PSS-4 } \\
\hline Model 1 & -0.06 & -0.12 & -0.01 & 0.02 & -0.05 & -0.11 & 0.00 & 0.04 \\
\hline Model 2 & -0.07 & -0.13 & -0.02 & 0.01 & -0.04 & -0.09 & 0.01 & 0.15 \\
\hline Model 3 & -0.05 & -0.12 & 0.01 & 0.11 & -0.14 & -0.20 & -0.07 & $<.0001$ \\
\hline \multicolumn{9}{|l|}{ SQD-P } \\
\hline Model 1 & -0.05 & -0.10 & 0.005 & 0.07 & 0.11 & 0.06 & 0.16 & $<.0001$ \\
\hline Model 2 & -0.05 & -0.11 & 0.004 & 0.07 & 0.09 & 0.03 & 0.14 & 0.001 \\
\hline Model 3 & 0.02 & -0.07 & 0.12 & 0.65 & 0.00 & -0.09 & 0.09 & 0.93 \\
\hline \multicolumn{9}{|l|}{ SQD-D } \\
\hline Model 1 & -0.05 & -0.10 & 0.004 & 0.07 & 0.14 & 0.09 & 0.19 & $<.0001$ \\
\hline Model 2 & -0.06 & -0.12 & -0.01 & 0.03 & 0.13 & 0.08 & 0.18 & $<.0001$ \\
\hline Model 3 & -0.04 & -0.13 & 0.04 & 0.33 & 0.15 & 0.07 & 0.23 & 0.0004 \\
\hline
\end{tabular}

Model 1 obtained from multivariable-adjusted linear regression including age and sex

Model 2 obtained from multivariable-adjusted linear regression including age, sex, living area, educational level, household income, marital status, number of cohabitants, occupational class, history of chronic diseases, diagnosis of $\geq 1$ diseases during lockdown and use of psychoactive drugs before or during lockdown

Model 3 as in model 2 and including all psychometric scales simultaneously. Significant associations surviving Bonferroni correction for multiple testing $(\alpha=0.01)$ are highlighted in bold

$P H Q$-9 Patients' Health questionnaire, GAD-7 General anxiety disorder scale, PSS-4 Perceived stress scale, SQD Screening Questionnaire for Disaster Mental Health, $S Q D-P$ Post-traumatic Stress Disorder, $S Q D-D$ Depressive symptoms

However, our results should be interpreted in light of some limitations. First, the ALT RISCOVID-19 is a web-based survey with potential selection bias and selfreported information that may lead to misreporting. However, our analyses also rely on data collected within the Moli-LOCK study which includes participants from a well-established population-based prospective cohort who were telephone-interviewed and this limits misreporting. Both cohorts used retrospective data; thus recall bias cannot be excluded and changes in dietary intakes were self-reported rather than assessed objectively through administration of dietary questionnaires before and after lockdown. Another limitation is the lack of assessment of some personality variables of the participants, such as psychological resilience, which has a clear influence on the psychological distress that a person can present in a situation like this of confinement.
Finally, this study was conceived to test the hypothesis that lockdown-induced psychological distress could be unfavourably associated with changes in diet quality during confinement; however the direction of the association cannot be derived, due to our cross-sectional design.

It might be possible that mental distress could result in dietary changes [48]; however, robust longitudinal data in recent years have strengthened the evidence that healthy diets may reduce the risk of depressive symptoms [49], while Western-like diets and processed foods are independent predictors of depression and anxiety [47, 50].

Whatever the cause-effect relation, the present findings show that during confinement resulting from the COVID19 outbreak psychological distress and diet quality were closely related. 


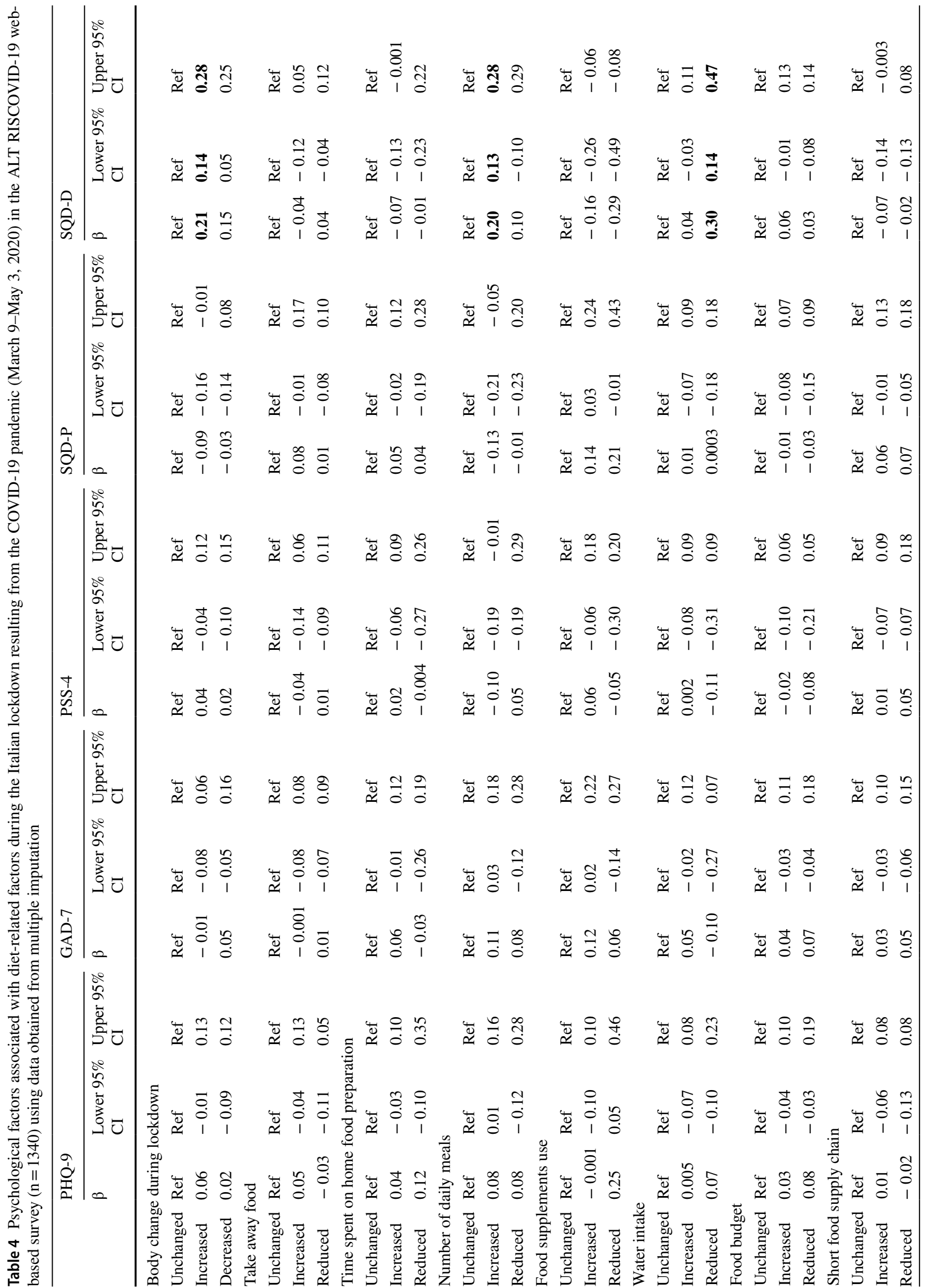




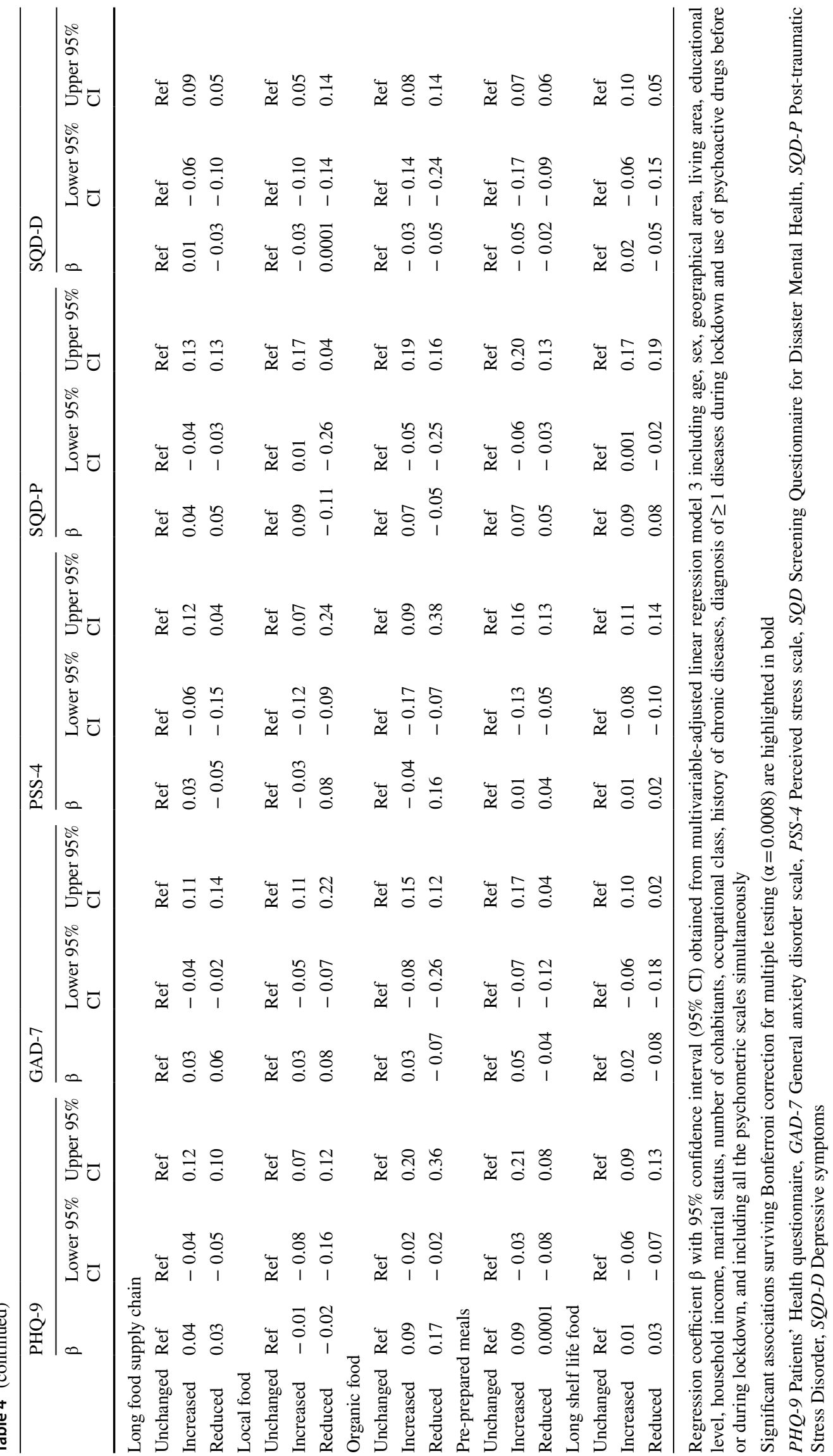




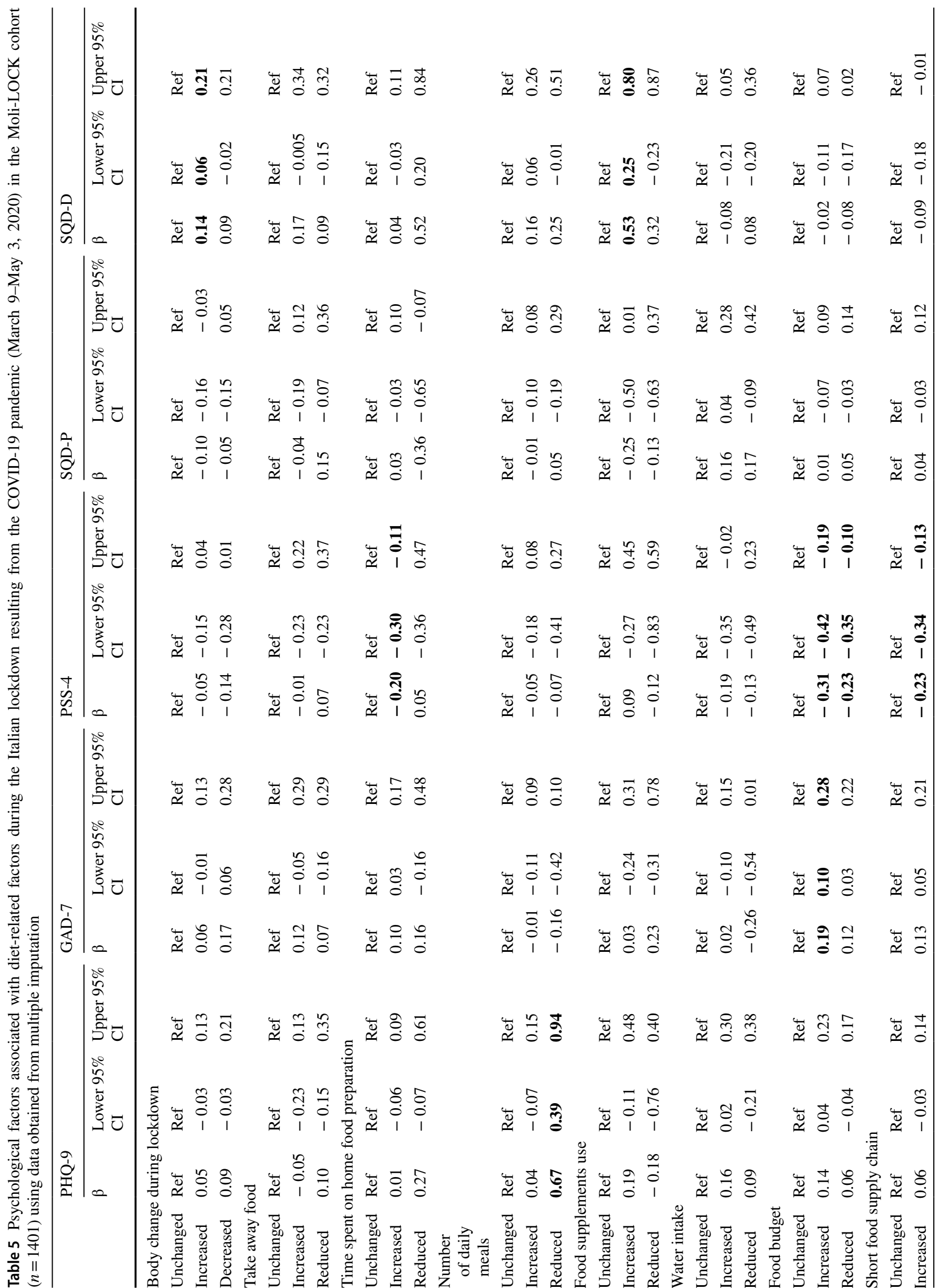




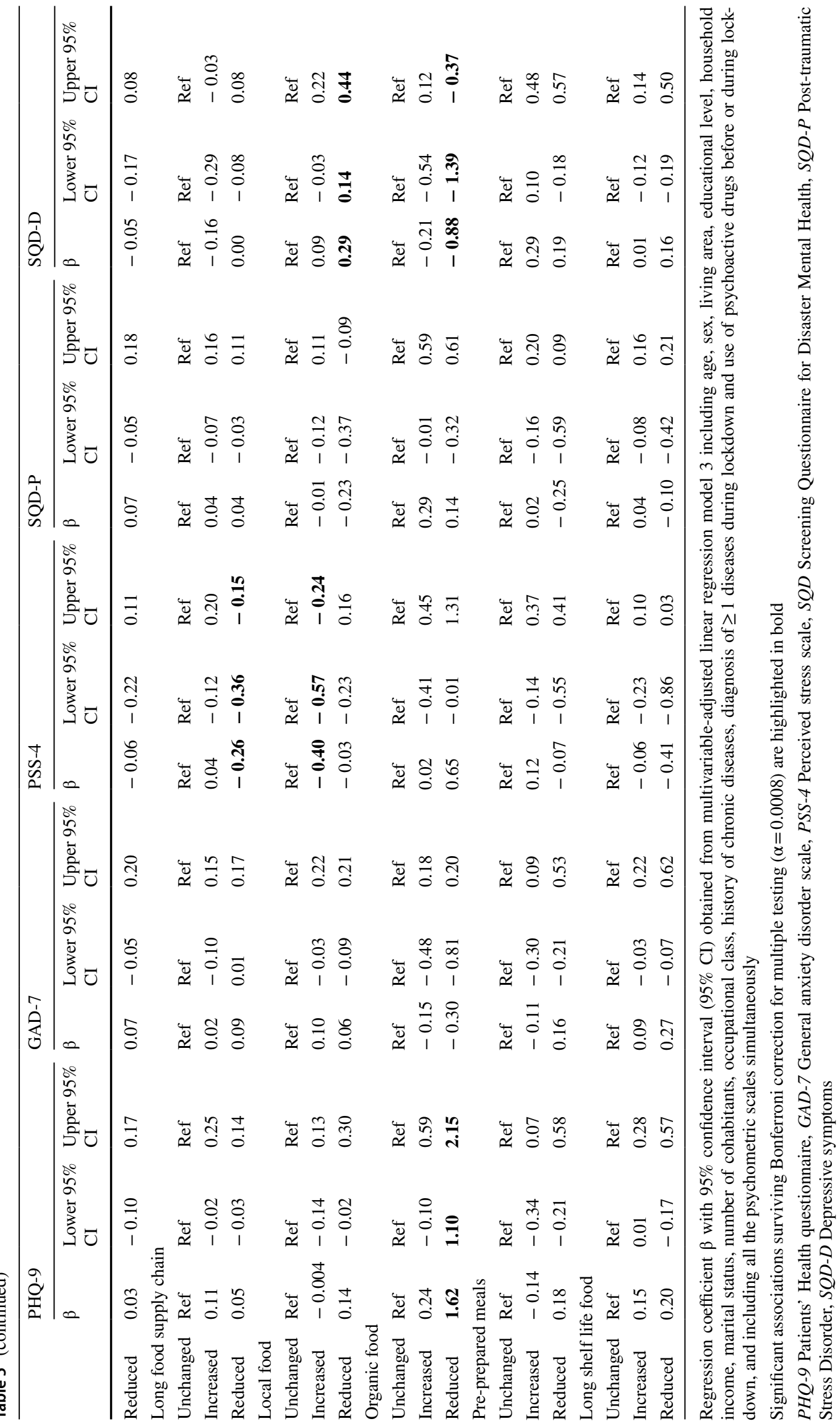




\section{Conclusions}

Psychological distress resulting from confinement due to the COVID-19 pandemic is directly associated with unhealthy dietary modifications among Italians, as reflected by a decrease in MD and an increase of UPF. A major role was found for depressive symptoms that may occur after a traumatic life event which seems to drive much of the observed association between psychological distress and changes towards unhealthy eating.

In view of possible future restrictive measures to contain the pandemic spread, which is far from being presently tamed, public health actions are warranted to mitigate the potential impact of psychological distress on diet quality. Indeed, psychological distress has direct and indirect effects on health and part of its harmful impact may also be mediated by unhealthy behaviours, such as an unfavourable diet which is a major modifiable risk factor of death globally [50].

Supplementary Information The online version contains supplementary material available at https://doi.org/10.1007/s00394-021-02752-4.

Acknowledgements We are grateful to the Moli-sani Study participants who enthusiastically joined the Moli-LOCK Study, to the citizens throughout Italy who adhered to our research effort and to the Associazione Cuore Sano ONLUS (Campobasso, Italy) for its cultural support. We thank Drs. Elisa Lombardozzi and Caterina Gianfrancesco from the IRCCS NEUROMED in Pozzilli, Italy, who helped us disseminate the ALT RISCOVID-19 web-based survey.

Author contribution LI, MB and AG conceived and designed the study. FB, ER, MP, SE acquired the data. SC and MO managed the data. $\mathrm{MB}$ and ADC analysed the data. MB drafted the manuscript. SC, CC, MBD, GdG and LI critically revised the questionnaire and this manuscript. All authors gave final approval and agree to be accountable for all aspects of the work ensuring integrity and accuracy.

Funding This work was partially supported by the Lombardy Region (DG-Welfare n. 7082/2020), the AXA Research Fund (Mitigating risk in the wake of the Covid-19 Pandemic), and the Italian Ministry of Health (CF RETE CARDIO-RCR-2020-23670065). The funders had no role in study design, data collection, analysis, interpretation and writing of the manuscript.

Availability of data The data underlying this article will be shared on reasonable request to the corresponding author. The data are stored in an institutional repository (https://repository.neuromed.it) and access is restricted by the ethical approvals and the legislation of the European Union.

\section{Declarations}

Conflict of interest The authors declare that they have no competing interests.

\section{References}

1. Coronavirus Resource Center at Johns Hopkins University. https:// coronavirus.jhu.edu/map.html. Accessed 10 Nov 2020

2. http://www.salute.gov.it/portale/nuovocoronavirus/dettaglioN otizieNuovoCoronavirus.jsp?lingua $=$ italiano $\&$ menu $=$ notizie $\& p=$ dalministero\&id=4184 Accessed 22 Oct 2020

3. Oliver G, Wardle J, Gibson EL (2000) Stress and food choice: a laboratory study. Psychosom Med 62:853-865. https://doi.org/10. 1097/00006842-200011000-00016

4. Lampuré A, Schlich P, Deglaire A, Castetbon K, Péneau S, Hercberg S, Méjean C (2015) Sociodemographic, psychological, and lifestyle characteristics are associated with a liking for salty and sweet tastes in French adults. J Nutr 145:587-594. https://doi.org/ 10.3945/jn.114.201269

5. Kontogianni MD, Vijayakumar A, Rooney C, Noad RL, Appleton KM, McCarthy D, Donnelly M, Young IS, McKinley MC, McKeown PP, Woodside JV (2020) A high polyphenol diet improves psychological well-being: the polyphenol intervention trial (PPhIT). Nutrients 12(8):2445. https://doi.org/10.3390/nu120 82445

6. Mueller M, Ganesh R, Bonnes S (2000) Gut Health = Mental Health? The Impact of Diet and Dietary Supplements on Mood Disorders. Curr Nutr Rep. https://doi.org/10.1007/ s13668-020-00340-2

7. Hawryluck L, Gold WL, Robinson S, Pogorski S, Galea S, Styra R (2004) SARS control and psychological effects of quarantine, Toronto, Canada. Emerg Infect Dis 10:1206-1212. https://doi.org/ 10.3201/eid1007.030703

8. Jeong H, Yim HW, Song YJ, Ki M, Min JA, Cho J, Chae JH (2016) Mental health status of people isolated due to Middle East Respiratory Syndrome. Epidemiol Health. 38:e2016048. https:// doi.org/10.4178/epih.e2016048

9. Brooks SK, Webster RK, Smith LE, Woodland L, Wessely S, Greenberg N, Rubin GJ (2020) The psychological impact of quarantine and how to reduce it: rapid review of the evidence. Lancet 395:912-920

10. Tang W, Hu T, Hu B, Jin C, Wang G, Xie C, Chen S, Xu J (2020) Prevalence and correlates of PTSD and depressive symptoms one month after the outbreak of the COVID-19 epidemic in a sample of home-quarantined Chinese university students. J Affect Disord 274:1-7. https://doi.org/10.1016/j.jad.2020.05.009

11. Moccia L, Janiri D, Pepe M, Dattoli L, Molinaro M, De Martin V, Chieffo D, Janiri L, Fiorillo A, Sani G, Di Nicola M (2020) Affective temperament, attachment style, and the psychological impact of the COVID-19 outbreak: an early report on the Italian general population. Brain Behav Immun 87:75-79. https://doi.org/ 10.1016/j.bbi.2020.04.048

12. Mazza C, Ricci E, Biondi S, Colasanti M, Ferracuti S, Napoli C, Roma P (2020) A Nationwide Survey of Psychological Distress among Italian People during the COVID-19 pandemic: immediate psychological responses and associated factors. Int J Environ Res Public Health 17:3165. https://doi.org/10.3390/ijerph17093165

13. Shi L, Lu ZA, Que JY, Huang XL, Liu L, Ran MS, Gong YM, Yuan K, Yan W, Sun YK, Shi J, Bao YP, Lu L (2020) Prevalence of and Risk Factors Associated With Mental Health Symptoms Among the General Population in China During the Coronavirus Disease 2019 Pandemic. JAMA Netw Open 3(7):e2014053. https://doi.org/10.1001/jamanetworkopen.2020.14053

14. Alzueta E, Perrin P, Baker FC, Caffarra S, Ramos-Usuga D, Yuksel D, Arango-Lasprilla JC (2020) How the COVID-19 pandemic has changed our lives: a study of psychological correlates across 59 countries. J Clin Psychol. https://doi.org/10.1002/jclp.23082

15. Burke T, Berry A, Taylor LK, Stafford O, Murphy E, Shevlin M, McHugh L, Carr A (2020) Increased Psychological Distress 
during COVID-19 and Quarantine in Ireland: a National Survey. J Clin Med 9:E3481. https://doi.org/10.3390/jcm9113481 (PMID: 33126707)

16. Deschasaux-Tanguy M, Druesne-Pecollo N, Esseddik Y, de Edelenyi FS, Allès B, Andreeva VA, Baudry J, Charreire H, Deschamps V, Egnell M, Fezeu LK, Galan P, Julia C, Kesse-Guyot E, LatinoMartel P, Oppert JM, Péneau S, Verdot C, Hercberg S, Touvier M (2021) Diet and physical activity during the coronavirus disease 2019 (COVID-19) lockdown (March-May 2020): results from the French NutriNet-Santé cohort study. Am J Clin Nutr 113:924-938

17. Rossinot H, Fantin R, Venne J (2020) Behavioral changes during COVID-19 confinement in France: a web-based study. Int J Environ Res Public Health 17(22):E8444. https://doi.org/10.3390/ ijerph17228444

18. Sarris J, Thomson R, Hargraves F, Eaton M, de Manincor M, Veronese N, Solmi M, Stubbs B, Yung AR, Firth J (2020) Multiple lifestyle factors and depressed mood: a cross-sectional and longitudinal analysis of the UK Biobank $(\mathrm{N}=84,860)$. BMC Med 18(1):354

19. Gialluisi A, Bonaccio M, Di Castelnuovo A, Costanzo S, De Curtis A, Sarchiapone M, Cerletti C, Donati MB, de Gaetano G, Iacoviello L, Moli-Sani Study Investigators (2020) Lifestyle and biological factors influence the relationship between mental health and low-grade inflammation. Brain Behav Immun 85:4-13

20. Lassale C, Batty GD, Baghdadli A, Jacka F, Sánchez-Villegas A, Kivimäki M, Akbaraly T (2019) Healthy dietary indices and risk of depressive outcomes: a systematic review and meta-analysis of observational studies. Mol Psychiatry 24:965-986. https://doi.org/ 10.1038/s41380-018-0237-8

21. Iacoviello L, Bonanni A, Costanzo S et al (2007) The MOLISANI Project, a randomized, prospective cohort study in the Molise region in Italy; design, rationale and objectives. Italian J Public Health 4:110-118

22. Kroenke K, Spitzer RL, Williams JB (2001) The PHQ-9: validity of a brief depression severity measure. J Gen Intern Med 16:606613. https://doi.org/10.1046/j.1525-1497.2001.016009606.x

23. Spitzer RL, Kroenke K, Williams JB, Löwe B (2006) A brief measure for assessing generalized anxiety disorder: the GAD-7. Arch Intern Med 166:1092-1097. https://doi.org/10.1001/archi nte.166.10.1092

24. Cohen S, Kamarck T, Mermelstein R (1983) A global measure of perceived stress. J Health Soc Behav 24:385-396

25. Valenti M, Fujii S, Kato H, Masedu F, Tiberti S, Sconci V (2013) Validation of the Italian version of the Screening Questionnaire for Disaster Mental Health (SQD) in a post-earthquake urban environment. Ann Ist Super Sanita 49:79-85. https://doi.org/10. 4415/ANN_13_01_13

26. Herle M, Smith AD, Bu F, Steptoe A, Fancourt D (2021) Trajectories of eating behavior during COVID-19 lockdown: longitudinal analyses of 22,374 adults. Clin Nutr ESPEN 42:158-165

27. Bonaccio M, Di Castelnuovo A, Pounis G, De Curtis A, Costanzo S, Persichillo M, Cerletti C, Donati MB, de Gaetano G, Iacoviello L, Moli-sani Study Investigators (2017) Relative contribution of health-related behaviours and chronic diseases to the socioeconomic patterning of low-grade inflammation. Int J Public Health 62:551-562

28. Schwingshackl L, Hoffmann G (2014) Mediterranean dietary pattern, inflammation and endothelial function: a systematic review and meta-analysis of intervention trials. Nutr Metab Cardiovasc Dis 24:929-939. https://doi.org/10.1016/j.numecd.2014.03.003

29. Yuan N, Chen Y, Xia Y, Dai J, Liu C (2019) Inflammation-related biomarkers in major psychiatric disorders: a cross-disorder assessment of reproducibility and specificity in 43 meta-analyses. Transl Psychiatry 18(9):233. https://doi.org/10.1038/s41398-019-0570-y

30. Fullana MA, Hidalgo-Mazzei D, Vieta E, Radua J (2020) Coping behaviors associated with decreased anxiety and depressive symptoms during the COVID-19 pandemic and lockdown. J Affect Disord 275:80-81. https://doi.org/10.1016/j.jad.2020.06. 027

31. Werneck AO, Silva DRD, Malta DC, Souza-Júnior PRB, Azevedo LO, Barros MBA, Szwarcwald CL (2020) Lifestyle behaviors changes during the COVID-19 pandemic quarantine among 6,881 Brazilian adults with depression and 35,143 without depression. Cien Saude Colet 25:4151-4156

32. Marty L, de Lauzon-Guillain B, Labesse M, Nicklaus S (2020) Food choice motives and the nutritional quality of diet during the COVID-19 lockdown in France. Appetite 15(157):105005. https:// doi.org/10.1016/j.appet.2020.105005

33. Ramalho SM, Trovisqueira A, de Lourdes M, Gonçalves S, Ribeiro I, Vaz AR, Machado PPP, Conceição E (2021) The impact of COVID-19 lockdown on disordered eating behaviors: the mediation role of psychological distress. Eat Weight Disord. https://doi. org/10.1007/s40519-021-01128-1

34. Cecchetto C, Aiello M, Gentili C, Ionta S, Osimo SA (2021) Increased emotional eating during COVID-19 associated with lockdown, psychological and social distress. Appetite 160:105122. https://doi.org/10.1016/j.appet.2021.105122

35. Blom V, Lönn A, Ekblom B, Kallings LV, Väisänen D, Hemmingsson E, Andersson G, Wallin P, Stenling A, Ekblom Ö, Lindwall M, Salier Eriksson J, Holmlund T, Ekblom-Bak E (2021) Lifestyle Habits and Mental Health in Light of the Two COVID19 Pandemic Waves in Sweden, 2020. Int J Environ Res Public Health 18(6):3313

36. Sadeghi O, Keshteli AH, Afshar H, Esmaillzadeh A, Adibi P (2019) Adherence to Mediterranean dietary pattern is inversely associated with depression, anxiety and psychological distress. Nutr Neurosci 11:1-12. https://doi.org/10.1080/1028415X.2019. 1620425

37. Bonaccio M, Di Castelnuovo A, Costanzo S, Pounis G, Persichillo M, Cerletti C, Donati MB, de Gaetano G, Iacoviello L (2018) Mediterranean-type diet is associated with higher psychological resilience in a general adult population: findings from the Molisani study. Eur J Clin Nutr 72:154-160

38. Masana MF, Tyrovolas S, Kolia N, Chrysohoou C, Skoumas J, Haro JM, Tousoulis D, Papageorgiou C, Pitsavos C, Panagiotakos DB (2019) Dietary patterns and their association with anxiety symptoms among older adults: the ATTICA study. Nutrients 11(6): 1250

39. Nicolaou M, Colpo M, Vermeulen E, Elstgeest LEM, Cabout M, Gibson-Smith D, Knuppel A, Sini G, Schoenaker DAJM, Mishra GD, Lok A, Penninx BWJH, Bandinelli S, Brunner EJ, Zwinderman AH, Brouwer IA, Visser M (2020) Association of a priori dietary patterns with depressive symptoms: a harmonised metaanalysis of observational studies. Psychol Med 50:1872-1883

40. Ruiz-Estigarribia L, Martínez-González MÁ, Díaz-Gutiérrez J, Sánchez-Villegas A, Lahortiga-Ramos F, Bes-Rastrollo M (2019) Lifestyles and the risk of depression in the "Seguimiento Universidad de Navarra" cohort. Eur Psychiatry 61:33-40. https://doi. org/10.1016/j.eurpsy.2019.06.002

41. Adjibade M, Julia C, Allès B, Touvier M, Lemogne C, Srour B, Hercberg S, Galan P, Assmann KE, Kesse-Guyot E (2019) Prospective association between ultra-processed food consumption and incident depressive symptoms in the French NutriNet-Santé cohort. BMC Med 17(1):78

42. Gómez-Donoso C, Sánchez-Villegas A, Martínez-González MA, Gea A, Mendonça RD, Lahortiga-Ramos F, Bes-Rastrollo M (2020) Ultra-processed food consumption and the incidence of depression in a Mediterranean cohort: the SUN Project. Eur J Nutr 59:1093-1103

43. Ruggiero E, Esposito S, Costanzo S, Di Castelnuovo A, Cerletti $\mathrm{C}$, Donati MB, de Gaetano G, Iacoviello L, Bonaccio M, INHES Study Investigators (2021) Ultra-processed food consumption and 
its correlates among Italian children, adolescents and adults from the Italian Nutrition \& Health Survey (INHES) cohort study. Public Health Nutr 24:1-14

44. Sin NL (2016) The Protective Role of Positive Well-Being in Cardiovascular Disease: Review of Current Evidence, Mechanisms, and Clinical Implications. Curr Cardiol Rep 18:106. https://doi. org/10.1007/s11886-016-0792-z

45. Kivimäki M, Steptoe A (2018) Effects of stress on the development and progression of cardiovascular disease. Nat Rev Cardiol $15: 215-229$

46. Pagliai G, Dinu M, Madarena MP, Bonaccio M, Iacoviello L, Sofi F (2020) Consumption of ultra-processed foods and health status: a systematic review and meta-analysis. Br J Nutr 14:1-11. https:// doi.org/10.1017/S0007114520002688

47. Lane MM, Davis JA, Beattie S, Gómez-Donoso C, Loughman A, O’Neil A, Jacka F, Berk M, Page R, Marx W, Rocks T (2020) Ultraprocessed food and chronic noncommunicable diseases: A systematic review and meta-analysis of 43 observational studies. Obes Rev. https://doi.org/10.1111/obr.13146
48. Richard A, Rohrmann S, Vandeleur CL, Mohler-Kuo M, Eichholzer M (2015) Associations between fruit and vegetable consumption and psychological distress: results from a populationbased study. BMC Psychiatry 15:213. https://doi.org/10.1186/ s12888-015-0597-4

49. Lai JS, Hiles S, Bisquera A, Hure AJ, McEvoy M, Attia J (2014) A systematic review and meta-analysis of dietary patterns and depression in community-dwelling adults. Am J Clin Nutr 99:181-197

50. Sánchez-Villegas A, Toledo E, de Irala J, Ruiz-Canela M, PlaVidal J, Martínez- González MA (2012) Fast-food and commercial baked goods consumption and the risk of depression. Public Health Nutr 15:424-432

51. Dai H, Much AA, Maor E, Asher E, Younis A, Xu Y, Lu Y, Liu X, Shu J, Bragazzi NL (2020) Global, regional, and national burden of ischemic heart disease and its attributable risk factors, 1990 2017: results from the global Burden of Disease Study 2017. Eur Heart J Qual Care Clin Outcomes. https://doi.org/10.1093/ehjqc co/qcaa076 